\title{
Effect of Solar Tracking on the Economic Viability of a Large-Scale PV Power Plant
}

\author{
Ephraim Bonah AGYEKUM*1, Bright Kwame AFORNU², Michael Nii Sanka ANSAH ${ }^{3}$ \\ ${ }^{1}$ Ural Federal University named after the first President of Russia Boris Yeltsin, Department of Nuclear \\ and Renewable Energy, 620002, 19 Mira Street, Ekaterinburg, Russia \\ ${ }^{2,3}$ Tomsk Polytechnic University, Lenin Avenue, 30, 634050, Tomsk, Russia
}

\begin{abstract}
This paper evaluated the economic potential of three different photovoltaic energy technologies at a selected site, Wa, in the Upper West region of Ghana. The cost of energy and net present value metrics were used to ascertain the cost-effectiveness of these technologies (fixed, single and double axis tracker systems). From the analysis, all three technologies are economically viable at the selected site, however, a sensitivity analysis shows that the fixed axis tracker is unviable at a discount rate above $2 \%$ whiles that of the single and double axis power plants also become impracticable at a discount rate above $6 \%$ using the financial input parameters adopted for the study. This is an indication that, even though the selected site may have the required solar radiation for the development of large-scale PV power plant, there is the need to create the necessary conducive financial environment to enable such projects to become viable. The double axis tracking system was identified as the optimum system that should be deployed at the selected site to get the best in terms of affordability of electricity to consumers and equity payback.
\end{abstract}

Keywords - Economic viability; Ghana; renewable energy; solar tracking system; solar power plant

\begin{tabular}{lll}
\hline Nomenclature & & \\
IEA & International Energy Agency & - \\
GW & Gigawatts & - \\
STS & Solar Tracking System & - \\
NPV & Net Present Value & $\$$ \\
COE & Cost of Energy & $\$ / \mathrm{kWh}$ \\
EPC & Energy Production Cost & $\$ / \mathrm{kWh}$ \\
O\&M & Operation and Maintenance & - \\
MW & Megawatt & - \\
T\&D & Transmission and Distribution & - \\
kWh & Kilowatt hour & - \\
MIRR & Modified Internal Rate of Return & $\%$ \\
IRR & Internal Rate of Return & $\%$ \\
\hline
\end{tabular}

* Corresponding author.

E-mail address: agyekumephraim@yahoo.com

(C)2020 Ephraim Bonah Agyekum, Bright Kwame Afornu, Michael Nii Sanka Ansah.

This is an open access article licensed under the Creative Commons Attribution License (http://creativecommons.org/

licenses/by/4.0), in the manner agreed with Sciendo. 


\section{INTRODUCTION}

In recent years, issues such as the need to ensure energy security, advancement in technology and the decreasing cost of most renewable energy systems as in the case of photovoltaic (PV) technology has led to the rapid development of renewable energy around the world [1]-[6]. Information from the International Energy Agency (IEA) shows that the PV market experienced an enormous growth in 2016, almost $76 \mathrm{GW}$ was installed during that period worldwide [3]. Research has shown a direct correlation between access to energy and the development of a country [7]. Hence the need to ensure that majority of the people have access to clean, cost effective and safer sources of energy generation to help in their economic growth.

Increasing demand for energy as a result of growing population, industrialization and urbanization coupled with depleting fossil fuel resources around the world has led to the need to find more sustainable sources of energy. Solar energy is one of such sustainable energies that has catch the attention of world leaders and investors. A photovoltaic solar system consisting of trackers, solar array units and other components that support the system employs photovoltaic elements to increase its efficiency [8]-[10].

In order to make good use of the energy from the sun, the modules are usually slanted towards the equator at an optimum tilt angle. The climatic conditions and the latitude of the site determines the tracking angle. Two solar tracking systems (STS) namely: single STS and double axis STS depends on the movement of degree of freedom. A single STS is a method of tracking the direction of the sun from one point to another using a single pivot point for the rotation. The two axis STS is a technique which tracks the sun path in two different axes with the help of two pivot points for rotation, the STS in this technology has both vertical and horizontal axis [11]-[13].

Several countries in the world are finding more sustainable, efficient and affordable sources of energy and Ghana is no exception. The government have a target to increase the percentage of renewable energy in the energy generation mix by some $10 \%$. This paper evaluated the economics of a large-scale solar power plant to be constructed in the Upper-West region in Ghana. This was done by using different tracking modes to assess the best technology for the selected site, using the cost of energy (COE) and net present value (NPV) financial metrics. This work is intended to provide policymakers and investors with the required information about all three technologies relative to their techno-economic viability to enable them to select the optimum technology as well as create deliberate policies that will help in the development of the sector. The study is divided into 4 main sections, section 1 has the introduction, section 2 provides the methodology adopted for the analysis, the results are presented in section 3, whiles the conclusion and some recommendations are also presented in section 4.

\section{Methodology}

The RETScreen is a clean energy management system software for evaluating energy efficiency, cogeneration project viability and performance of yet to be commenced (i.e. feasibility) as well as ongoing renewable energy projects. This paper used the RETScreen software to access the techno-economic potential of a $10 \mathrm{MW}$ solar power plant (SPP) at Wa. The selected site is located on latitude $10.1^{\circ} \mathrm{N}$ and longitude $-2.5^{\circ} \mathrm{E}$. The daily solar radiation horizontal for the selected region according to the National Aeronautics and Space 
Administration (NASA) using RETScreen, is $5.57 \mathrm{kWh} \mathrm{m}^{-2} \mathrm{~d}^{-1}$ with a wind speed average of $2.2 \mathrm{~m} / \mathrm{s}$ at a height of $10 \mathrm{~m}$ per year. This research used the cost of energy (COE) metric to assess the economic viability of the modelled power project. The COE is the ratio of the sum of the entire cost accumulated during the project's lifetime to the unit of electricity generated over the entire lifetime of the project [2]. The COE and NPV can be computed using Eq. (1) and Eq. (2), respectively [14]. Three different tracking modes were employed in this paper, it includes, fixed, single-axis and double axis trackers as indicated in Fig. 1.

The analysis was conducted using the following financial parameters: inflation rate of $2 \%$ and debt term of 15 years as used in [15], debt ratio of $70 \%$ and discount rate of $9 \%$.

$$
C O E=\frac{-C_{0}-\frac{\sum_{n=1}^{N} C_{n}}{\left(1+d_{\text {nominal }}\right)^{n}}}{\frac{\sum_{n=1}^{N} Q_{n}}{\left(1+d_{\text {real }}\right)^{n}}}
$$

Where: $C_{o}$ is the amount for the plant's equity investment, $C_{n}$ the cost of the project in $n$ years (this includes the operation and maintenance, installations, financial costs and fees), $d_{\text {real }}$ represents the real discount rate, $d_{\text {nominal }}$ is the nominal discount rate (discount rate with inflation inclusive), $N$ is the period for the analysis, $Q_{n}$ is the generated electricity by the project in year $n$.

$$
N P V=\sum_{n=0}^{N} \frac{C_{n}}{\left(1+d_{\text {nominal }}\right)^{n}}
$$

A positive NPV indicates that the project is economically viable, whiles a negative value indicates otherwise. The climatic data for the selected site is represented in Fig. 2. The solar radiation for the area is generally high in harmattan seasons i.e. the months of October, November, January, February, March, and April. It however peaks in the month of March. The rainy season of the area usually peak in June and July which accounts for the drop in solar radiation during that period as can be seen in the climatic data.

The technical parameters for the simulation are as indicated in Table 1. All parameters used for the study were obtained from the RETScreen software.

TABLE 1. TECHNICAL PARAMETERS USED FOR THE ANALYSIS

\begin{tabular}{lll}
\hline Parameter & Description/Value & Unit \\
\hline Photovoltaic type & Poly-Si & \\
Power capacity & 10000 & $\mathrm{~kW}$ \\
Manufacturer & Gintech & \\
Model & Poly-Si-GTE & \\
Number of units & $4240 \mathrm{M} 63$ & \\
Efficiency & 14.77 & $\%$ \\
Solar collector area & 68246 & $\mathrm{~m}^{2}$ \\
Inverter efficiency & 98 & $\%$ \\
\hline
\end{tabular}




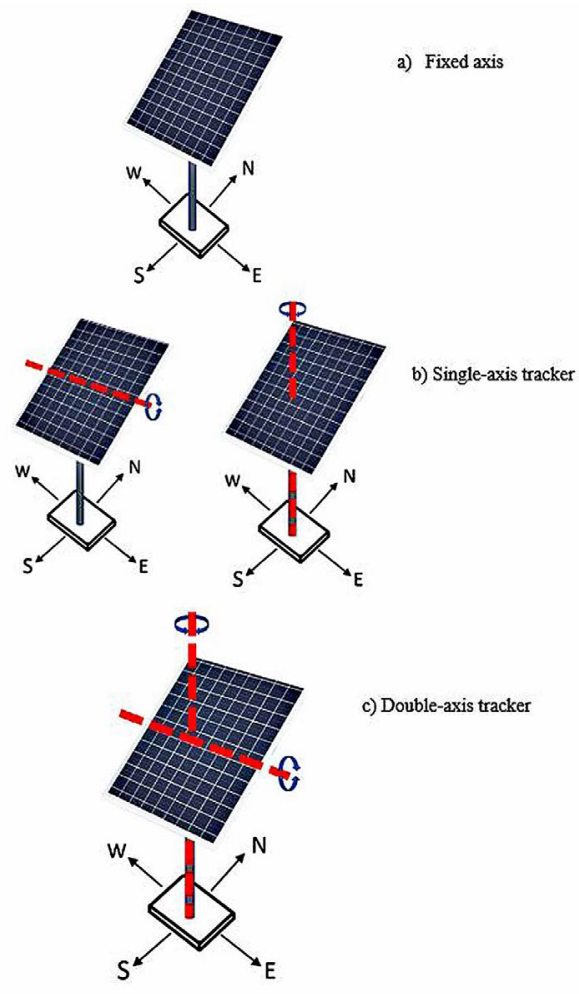

Fig. 1. Different tracking types for PV Power Plant (authors' elaboration).
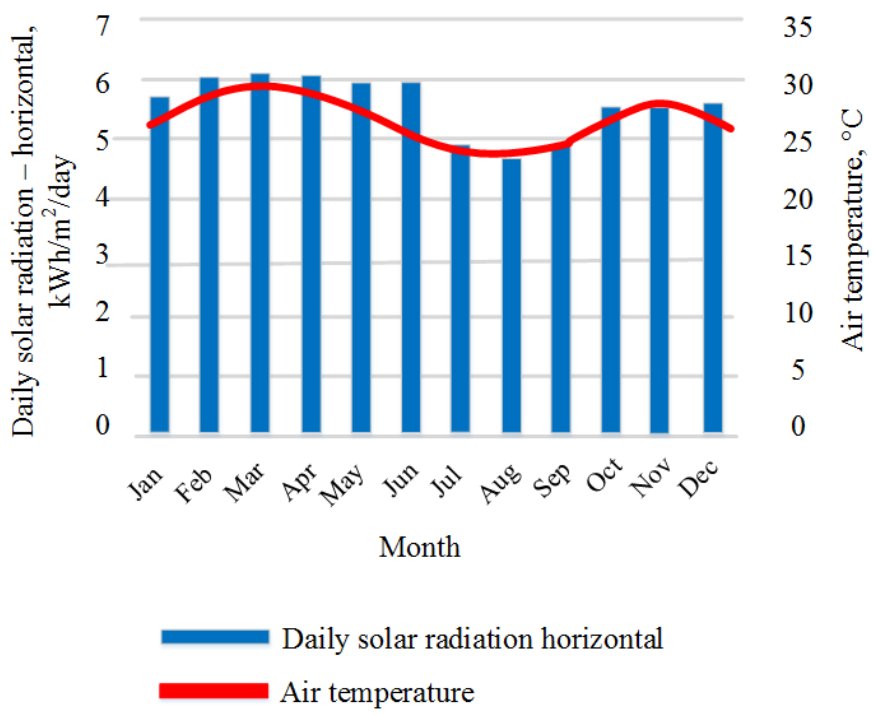

Fig. 2. Monthly average climatic data for the selected site (obtained from RETScreen, NASA data). 


\section{Results}

This section evaluated the impact of tracking on the economic viability of a $10 \mathrm{MW} \mathrm{PV}$ power plant by analysing the EPC and NPV of all three scenarios. Evaluating a project's techno-economic viability before implementation helps engineers, governments and investors to take the right decisions relative to the implementation or otherwise of such projects. In the case of renewable energy projects which has a high initial capital cost, it gives both decision makers and investors the opportunity to know at first hand the possible long-term technoeconomic behaviour of the project. Fig. 3 to Fig. 5 shows the cumulative cash flow for the project under different tracking systems. It also indicates the simple payback period for all three scenarios.

The capacity factor which can be defined as the ratio of the actual electricity generated by a power plant to its maximum possible electricity output [16], in the case of the simulated plants are, $20.5 \%, 25.6 \%$ and $26.5 \%$ for the fixed, single and double axis trackers, respectively. The total initial cost for all three projects was \$ 43120000 using an initial capital cost of $1500 \$ / \mathrm{kWh}$ for the PV modules [17] and an operation and maintenance (O\&M) cost of $40 \$$ year [18] for all three scenarios. Table 2 shows the results obtained for the financial analysis of the different systems. The double axis tracker had a simple payback time of 11.6 years, the single axis tracker had 13.4 years whiles the fixed axis tracker recorded the longest period for the simple payback, which is 17.1 years. The differences in the years can be attributed to the differences in the intensity of solar irradiation received by the different systems due to the tracking system. The double axis tracking system recorded the least number of years because its mode of tracking results in greater irradiance relative to the other two modes or scenarios, since it minimizes losses due to the cosine effect through the use of its second axis of rotation.

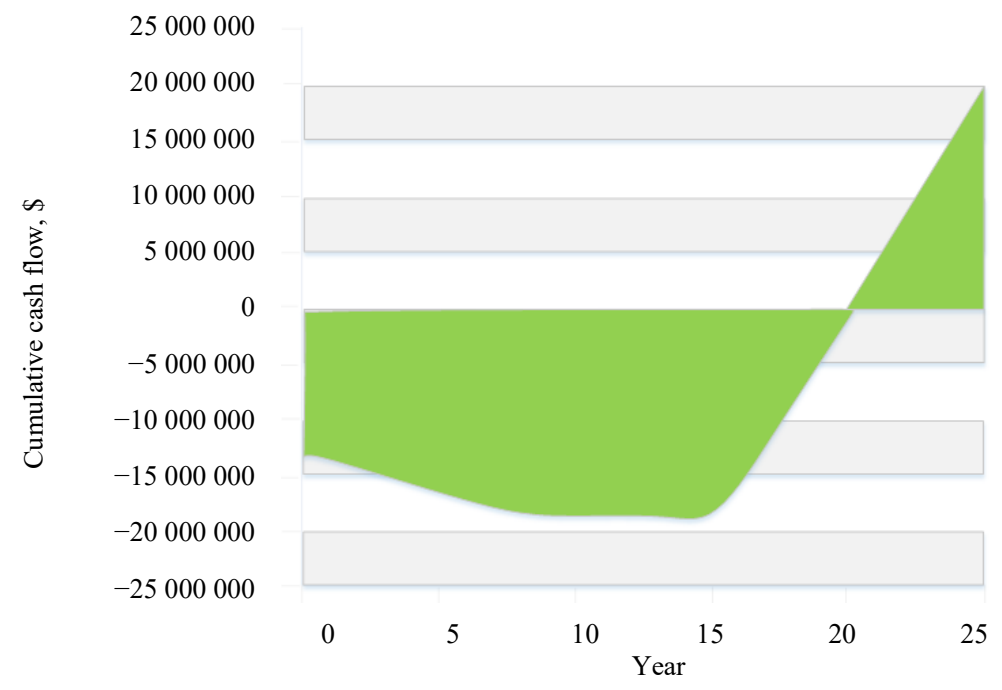

Fig. 3. Cumulative cash flow - fixed tracker. 


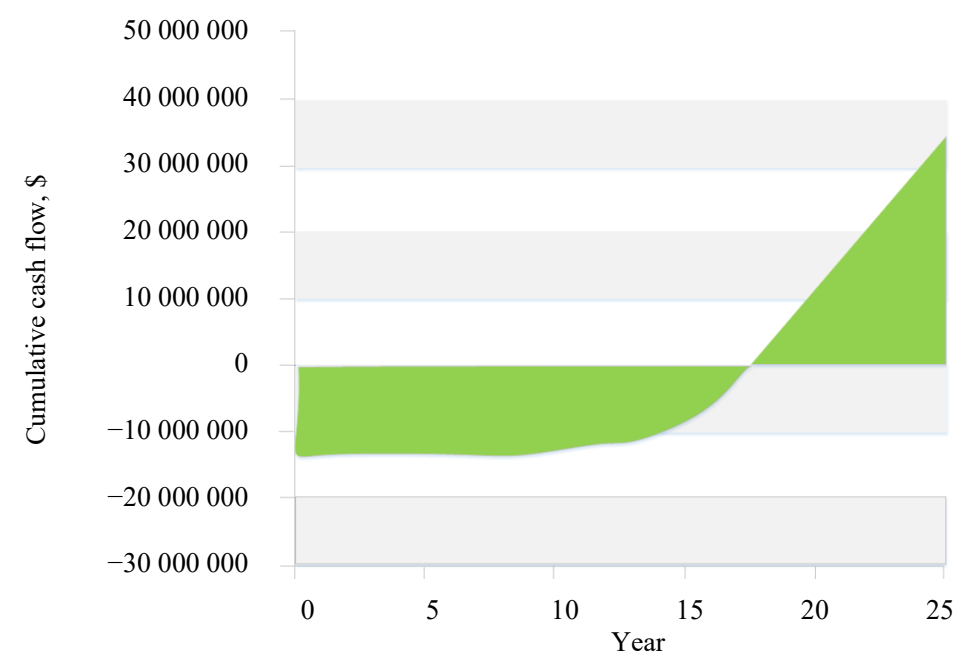

Fig. 4 Cumulative cash flow - Single axis tracker.

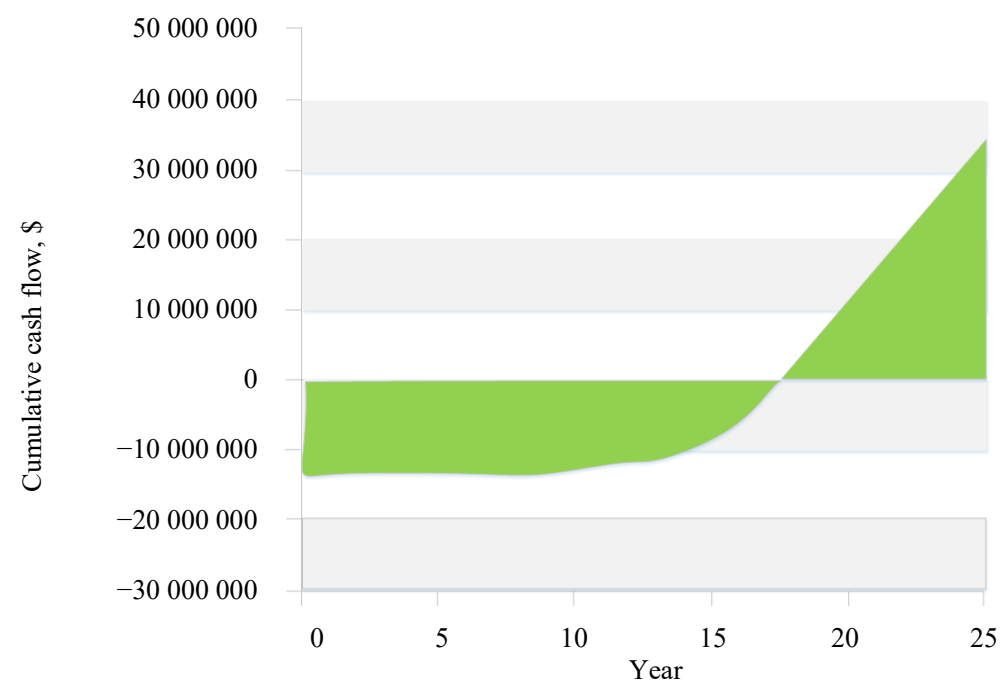

Fig. 5 Cumulative cash flow - Double axis tracker.

The obtained results indicate that, the tracking system has a direct effect on the COE or EPC, double STS had the least EPC, whiles the highest EPC was recorded under the fixed axis system. It is clear from the analysis that the payback year and the EPC of the project can be reduced by the use of tracking system.

The comparison of the three technologies as shown in Table 2 shows that the best technology for the reduction of greenhouse gas (GHG) emissions is the double axis tracking system. The RETScreen software provides GHG emission factor (excluding transmission and 
distribution (T\&D)) and GHG emission factor including (T\&D) for every country. In the case of Ghana, GHG factor excluding T\&D is $0.215 \mathrm{tCO}_{2} / \mathrm{MWh}$ and including a $7 \% \mathrm{~T} \& \mathrm{D}$ is $0.232 \mathrm{tCO}_{2} / \mathrm{MWh}$. We assumed a GHG reduction credit rate of $30 \$ / \mathrm{tCO}_{2}$ so as to compute the monetary value of the modelled project on the economy of Ghana, the rate usually varies between 1 and $100 \$ / \mathrm{tCO}_{2}$ depending on the country involved and their level of pollution [19]. The modelling gave a GHG reduction revenue of $213797 \$, 669215 \$$ and $682873 \$$ for the fixed, single and double axis tracking systems, respectively, using natural gas as a reference fuel.

The current cost of energy for electricity consumers in Ghana ranges between $15-19 \notin / \mathrm{kWh}$ for electricity generated from Ghana's conventional sources [2]. Comparing the obtained EPC for the various scenarios evaluated in this paper to the current cost of energy in Ghana means electricity generation from all three systems will be cheaper should any of them be developed.

TABLE 2. COMPARISON OF FINANCIAL VIABILITY

\begin{tabular}{|c|c|c|c|}
\hline Parameter & Fixed axis & Single axis & Double axis \\
\hline Pre-tax IRR equity, $\%$ & 3.9 & 6.7 & 7.1 \\
\hline Pre-tax MIRR equity, $\%$ & 5.1 & 7.2 & 7.6 \\
\hline Pre-tax IRR assets, \% & -1.2 & 0.47 & 0.74 \\
\hline Pre-tax MIRR assets, $\%$ & 0.81 & 2.3 & 2.6 \\
\hline Simple payback, years & 17.1 & 13.4 & 11.6 \\
\hline Equity payback, years & 20 & 17.5 & 17.1 \\
\hline NPV, \$ & -9856990 & -4564455 & -3659826 \\
\hline Annual life cycle savings, $\$$ year & -1003503 & -464690 & -372593 \\
\hline Benefit-Cost (B-C) ratio & 0.24 & 0.65 & 0.72 \\
\hline Debt service coverage & 0.78 & 0.92 & 0.94 \\
\hline GHG reduction cost, $\$ / \mathrm{tCO}_{2}$ & 141 & 57.42 & 16.37 \\
\hline Energy production cost (EPC), \$/kWh & 0.151 & 0.133 & 0.130 \\
\hline Annual electricity export to grid, MWh & 33082 & 37567 & 38334 \\
\hline Electricity export rate, $\$ / \mathrm{kWh}$ & 0.10 & 0.10 & 0.10 \\
\hline Annual electricity export revenue, $\$$ & 3308177 & 3756730 & 3833400 \\
\hline Gross GHG reduction, $\mathrm{tCO}_{2} /$ year & 7127 & 8093 & 22762 \\
\hline Gross GHG reduction -25 years, $\mathrm{tCO}_{2}$ & 178164 & 202322 & 569060 \\
\hline
\end{tabular}

\subsection{Sensitivity Analysis}

Since COE and NPV can be affected by economic and environmental vicissitudes, a sensitivity analysis was conducted to ascertain the impact of some financial parameters on the economic viability of the project. The discount and inflation rates were varied to unravel their effects on all three technologies. From the sensitivity analysis, it is clear that the economic viability of such projects hugely depends on the financing conditions. The obtained results suggest that the bankability of all three projects depends significantly on the inflation rate, the fixed system exhibited the highest susceptibility. Fig. 6 shows the sensitivity analysis of inflation rate on the NPV of the project. The impact of inflation and discount rate on the EPC is also significant, the EPC, increases with increasing inflation and discount rates as 
$2020 / 24$

indicated in Fig. 7 and Fig. 9. The fixed tracker has shown to be more susceptible to the type of financial conditions for the project, a discount rate of $4 \%$ and above renders the NPV negative as can be seen in Fig. 8, this indicates that fixed tracker projects will not be economically viable using the $9 \%$ discount rate in this study.

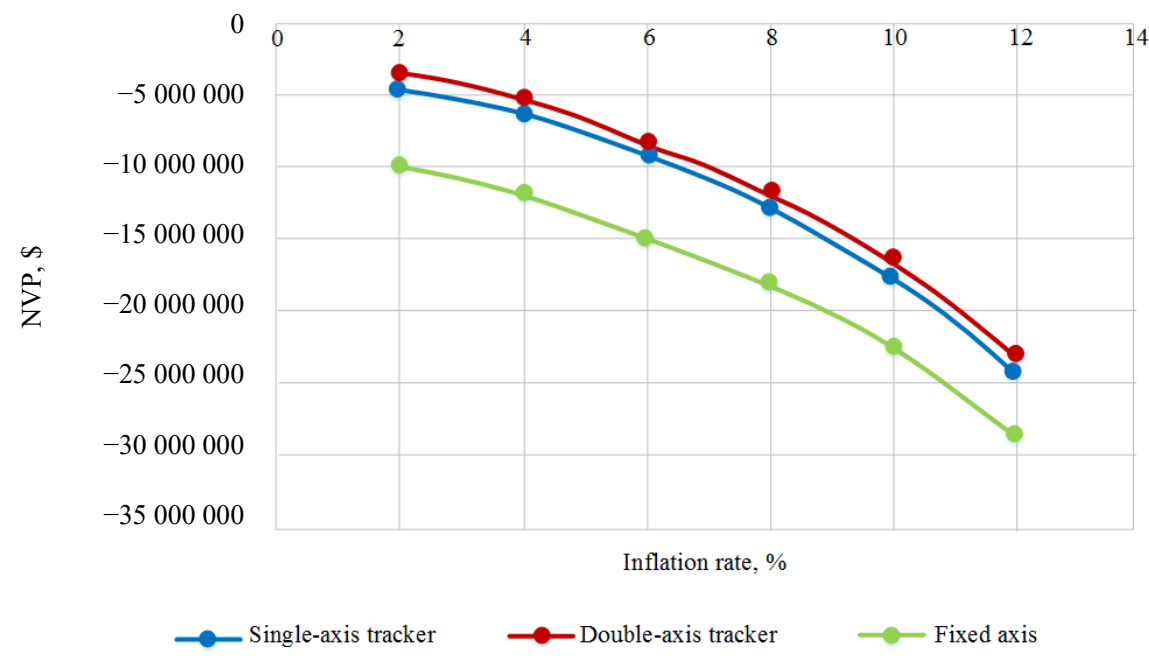

Fig. 6. Sensitivity Analysis on Inflation.

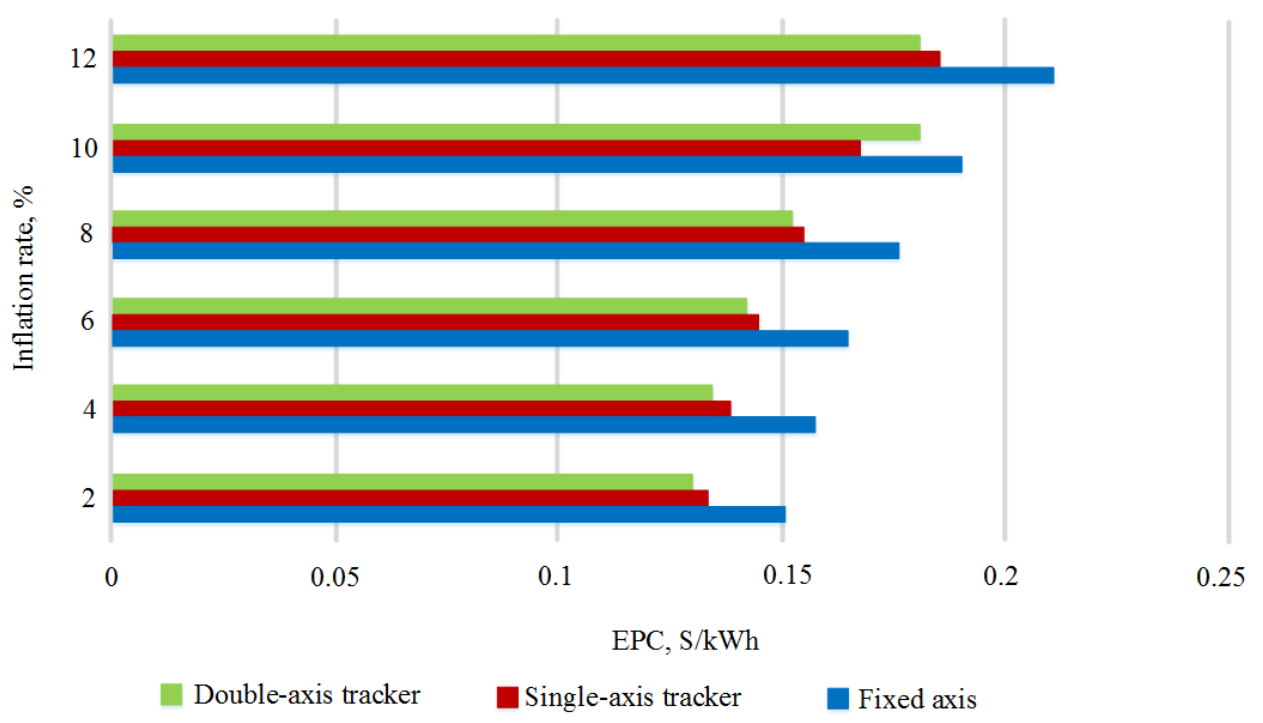

Fig. 7. Sensitivity analysis of inflation rate on EPC. 


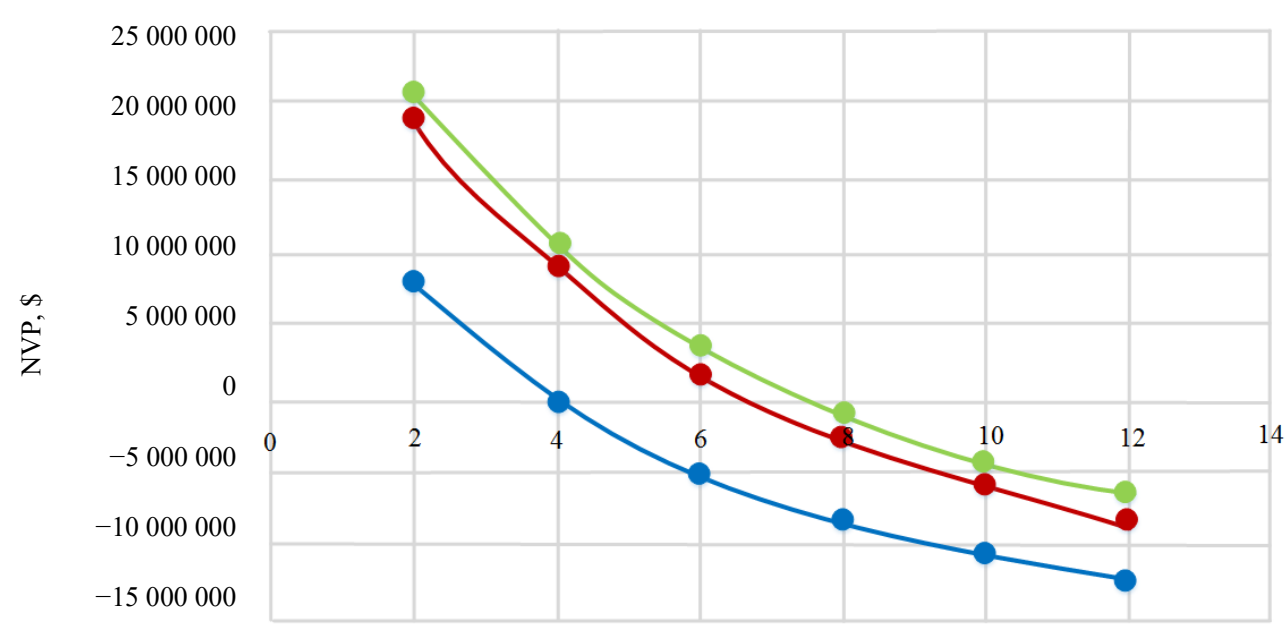

Discount rate, $\%$

$\longrightarrow$ Fixed axis $\longrightarrow$ Single-axis tracker $\quad \longrightarrow$ Double-axis tracker

Fig. 8. Sensitivity analysis of discount rate on NPV.

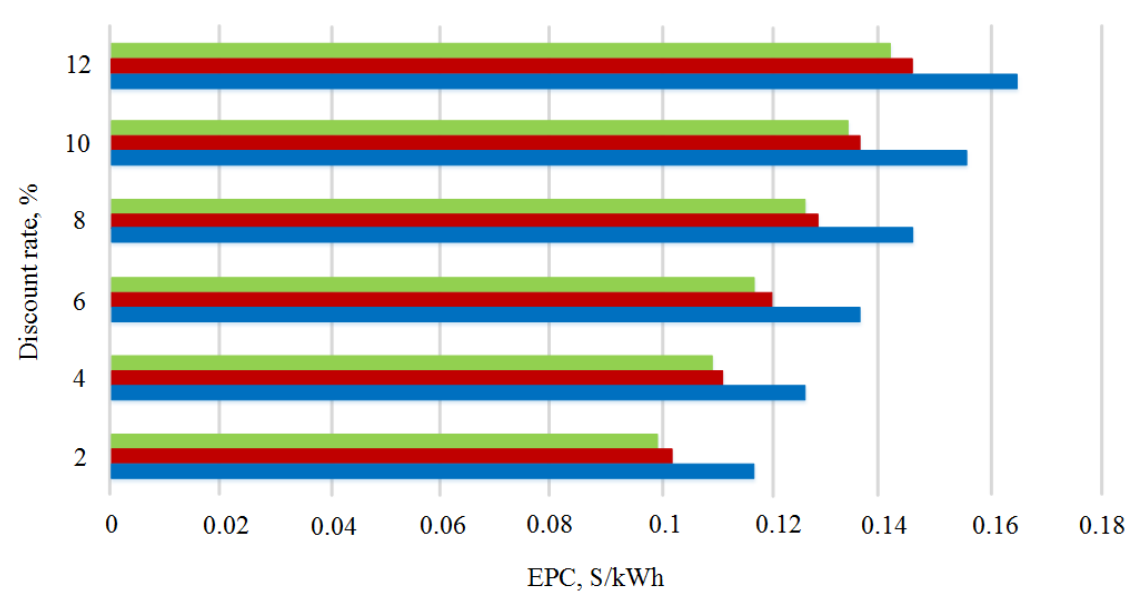

Double-axis tracker

Single-axis tracker

Fixed axis

Fig. 9. Sensitivity analysis of discount rate on EPC.

\section{Conclusion}

This study seeks to unravel the best technology for the development of PV power plant at the selected site in Ghana. From the analysis, the project has high economic prospects, however, the economic viability of the project is subject to its financing arrangement or conditions. All three different technologies are viable; however, the double STS shows more 
economic cost-effectives relative to the other technologies. From the analysis, an EPC of $0.151 \$ / \mathrm{kWh}, 0.133 \$ / \mathrm{kWh}$ and $0.130 \$ / \mathrm{kWh}$ were obtained for the fixed, single and double axis tracker systems, respectively. The NPV for all three scenarios turned negative which is an indication that all three projects cannot be bankable under the current financial arrangement used for the analysis. The most electricity export to grid was generated from the double-axis tracking system, exporting a total of $38334 \mathrm{MWh}$ to grid per annum, whereas the single-axis tracking system exported $37567 \mathrm{MWh}$, with the fixed axis system generating $33082 \mathrm{MWh}$ which is the least electricity to grid per annum. From the sensitivity analysis, the impact of both discount and inflation rates can not be underestimated if such project were to be economically viable. This means the role of the Ghanaian and other governments on the continent with similar solar radiation potentials in the economic viability of such projects is key. There is the need to create the conducive financial environment for such projects to thrive. For instance, the simulation suggests that a discount rate of $2 \%$ and above makes the fixed axis system unviable, the single and double axis tracker systems can only be viable with discount rate up to $6 \%$ under the current financial conditions used for the analysis. It is therefore important to create a financing scheme that favours such projects such as the creation of grants and incentives schemes for investors.

This paper recommends that, in order to comprehend the impact of other factors such as cost of land, ambient temperature, dust pollution and other financial conditions on the project, it is necessary to perform a future study which factors them to ascertain their effect on the PV system. Secondly, this paper assumed an equal initial capital cost for all technologies, it is instructive to note that, there may be some slight differences relative to the cost of fixed and tracking system.

\section{REFERENCES}

[1] Agyekum E. B., Velkin V. I., Hossain I. Comparative evaluation of renewable energy scenario in Ghana. IOP Conference Series: Materials Science and Engineering 2019:643(1):012157. https://doi.org/10.1088/1757$\underline{899 X / 643 / 1 / 012157}$

[2] Agyekum E. B., Velkin V. I., Hossain I. Sustainable energy: Is it nuclear or solar for African Countries? Case study on Ghana. Sustainable Energy Technologies and Assessments 2020:37:100630. https://doi.org/10.1016/j.seta.2020.100630

[3] Raff R., Golub V., Perko J. Comparative Analysis of an Off-grid PV System for Different Types of Batteries, International Journal of Electrical and Computer Engineering Systems 2018:9(1). https://doi.org/10.32985/ijeces.9.1.3

[4] Blumberga D., et al. Energy, Bioeconomy, Climate Changes and Environment Nexus. Environmental and Climate Technologies 2019:23(3):370-92. https://doi.org/10.2478/rtuect-2019-0102

[5] Alam S. S., Nor N. F. M., Ahmad M., Hashim N. H. N. A survey on renewable energy development in Malaysia: Current status, problems and prospects. Environmental and Climate Technologies 2016:17(1):5-17. https://doi.org/10.1515/rtuect-2016-0002

[6] Kittipongvises S. Feasibility of applying clean development mechanism and GHGs emission reductions in the gold mining industry: a case of Thailand. Environmental and Climate Technologies 2015:15(1):34-47. https://doi.org/10.1515/rtuect-2015-0004

[7] Agyekum E. B., Ansah M. N. S., Afornu K. B. Nuclear energy for sustainable development: SWOT analysis on Ghana's nuclear agenda. Energy Reports 2020:6:107-115. https://doi.org/10.1016/j.egyr.2019.11.163

[8] Kim K. H., Cho S. B. An efficient concentrative photovoltaic solar system with Bayesian selection of optimal solar tracking algorithms. Applied Soft Computing Journal 2019:83:105618. https://doi.org/10.1016/j.asoc.2019.105618

[9] Kim J. Y., Cho S. B. Electric energy consumption prediction by deep learning with state explainable autoencoder. Energies 2019:12(4):739. https://doi.org/10.3390/en12040739

[10] Velkin V. I. Research efficiency of complex systems with spread spectrum renewable energy for electric power supply decentralized objects in Russia. WIT Transactions on Ecology and the Environment 2014:190:437-444.

[11] Zhao D., et al. Influences of installation and tracking errors on the optical performance of a solar parabolic trough collector. Renewable energy 2016:94:197-212. http://dx.doi.org/10.1016/j.renene.2016.03.036

[12] Hafez A. Z., et al. Solar tracking systems: Technologies and trackers drive types - A review. Renewable and Sustainable Energy Reviews 2018:91:754-782. https://doi.org/10.1016/j.rser.2018.03.094 
[13] Theebhan M., Long C. Y., Tiong T. T. Design and development of a solar thermal collector with single axis solar tracking mechanism. MATEC Web of Conferences 2016:78:01002. https://doi.org/10.1051/matecconf/20167801002

[14] Aly A., et al. Is Concentrated Solar Power (CSP) a feasible option for Sub-Saharan Africa?: Investigating the technoeconomic feasibility of CSP in Tanzania. Renewable energy 2019:135:1224-40. https://doi.org/10.1016/j.renene.2018.09.065

[15] Pan Y., et al. Feasibility analysis on distributed energy system of Chongming County based on RETScreen software. Energy 2017:130:298-306. https://doi.org/10.1016/j.energy.2017.04.082

[16] National Renewable Energy Laboratory. Solar Energy and Capacity Value. Golden: NREL, 2013.

[17] International Renewable Energy Agency. Renewable Power Generation Costs in 2018. Abu Dhabi: IRENA, 2019.

[18] Agyekum E. B., Nutakor C. Feasibility study and economic analysis of stand-alone hybrid energy system for southern Ghana. Sustainable Energy Technologies and Assessments 2020:39:100695 https://doi.org/10.1016/j.seta.2020.100695

[19] Mirzahosseini A. H., Taheri T. Environmental, technical and financial feasibility study of solar power plants by RETScreen, according to the targeting of energy subsidies in Iran. Renewable and Sustainable Energy Reviews 2012:16(5):2806-11. https://doi.org/10.1016/j.rser.2012.01.066 